\title{
SOSIALISASI PEMBELAJARAN BAHASA INGGRIS BERBASIS MULTILITERACIES PADA SANTRI PONDOK RAUDLATUL MUBTADI'IN CISAMBENG
}

\author{
Rama Dwika Herdiawan*, Agus Rofi'i, Eka Nurhidayat, Afief Fakhruddin \\ Prodi Pendidikan bahasa Inggris FKIP Universitas Majalengka \\ *ramadwika@unma.ac.id
}

\begin{abstract}
The $21^{\text {st }}$ century learning maut be equipped by Concept of multiliteracies which covers understanding a number of information comprehensively as well as factually. In terms of community services activity, there is a close engagement from the boarding school students from primary, secondary, and college which are educated the material in line with the use of online learning platform and online learning media. From the result, it is indicated that the boarding school students seems to be spiritful to take a part in terms of doing the online test by using the laptops and mobile phones. They are also able to operate and employ the media and platform. e.g. they are able to differentiate the factual news and the hoax news which is indicated they could comprehend the spread of information wisely and based on the facts. The concept of multiliteracies can be well-implemented by integrating the existing role of digital technology with the material given and contributes to enhancing new insights in relation to the use of social media in learning English or educating them multiliterate in terms of creating learning environment based $21^{\text {st }}$ century multlliteracies.
\end{abstract}

Keywords: multiliteracies; english language learning

\begin{abstract}
Abstrak
Pembejaran abad ke 21 harus memliki konsep multiliteracies yang mencakup pemahaman informasi bersifat komprehensif dan factual. Dalam kegiatan sosialisasi ini, ada keteribatan para santri dari jenjang sekolah dasar, menengah, dan perguruan tinggi di lingkungan Pondok Pesantren Raudlatul Mubtadi'in yang diberikan pemaparan terkait penggunaan platform dan media pembelajaran dalam matapelajaran bahasa Inggris. Hasil kegiatan sosialisasi ini adalah para santri nampak sangat bersemangat dalam mengikuti pengerjaan soal-soal bahasa Inggris secara dalam jaringan dengan menggunakan laptop atau ponsel-ponsel yang dimiliki oleh santri. Dan juga para santri mampu mengoperasikan atau menggunakan media ataupun platform pembejaran dalam jarring secara baik dan komprehensif. Sebagai contoh santri dapat membedakan berita factual dan berita Hoax yang mana itu mengindikasikan bahwa santri dapat memahami informasi dengan bijak dan sesuai fakta. Konsep multiliterasi dapat diimplementasikan dalam bentuk pengintegrasian peran digital teknologi dengan materi yang terkait dan berkontribusi pada peningkatan wawasan baru dalam pemanafaatan sosial media dalam melaksanakan pembelajaran bahasa Inggris atau bisa dikatakan mahasiswa diarahkan menjadi pribadi yang multiliterate yang mana mahasiswa mampu menciptakan lingkungan belajar yang bernuansa multiliterasi pada abad ke 21 ini.
\end{abstract}

Kata Kunci: multiliteracies; pembelajaran bahasa inggris

\begin{tabular}{l|l|l} 
Submitted: $2021-09-14$ & Revised: $2021-10-14$ & Accepted: $2021-10-26$
\end{tabular}

\section{Pendahuluan}

Literasi dianggap sebagai kunci dalam kesuksesan hidup untuk saat ini. Tanpa adanya wawasan berliterasi, seseorang akan tertinggal jauh dari tahapan proses sosialisasi dalam praktek sosial. Pendidikan dijadikan sebagai pemicu berkembangnya keterampilan seseorang dalam berliterasi. Pada awalnya, kata literasi didefiniskan sebagai kemampuan membaca dan menulis dalam pengertian secara tradisional. Seiring kemajuan ilmu pengetahuan dan teknologi, ada perubahan pola pikir atau cara orang berkomunikasi dan bersosialiasi sehingga pembelajaran membaca dan menulis sebagai unsur keterampilan literasi perlu diimplementasikan dengan suatu perubahan dan penyesuaian (Cope \& Kalantzis, 2005) (Kalantzis \& Cope, 2008) (Cope \& Kalantzis, 2009). Effendy dalam pernyataannya (Kemendikbud, 2017) menyampaikan enam literasi dasar yang harus dimiliki oleh peserta didik yaitu literasi baca tulis, literasi numerasi, literasi sains, literasi digital, literasi finansial, dan literasi budaya dan kewargaan berdasarkan penetapan World Economic Forum pada tahun 2015 lalu. Keterampilan baca tulis sederhana harus didukung dengan 
berbagai keterampilan literasi yang lain. Oleh karena itu, peserta didik kini diarahkan untuk memiliki keterampilan berbagai literasi. Sebagai contoh, Pembelajaran bahasa Inggris dalam masa pandemic ini harus dilaksanakan secara virtual atau dalam jaringan (daring) yang mana peserta didik tentunya harus memiliki pemahaman yang lebih dalam mengikuti serangkaian kegiatan pembelajaran baik secara berkelompok ataupun individual dalam rangka menambah dan memperluas kompentensi berbahasa yang baik. Oleh karena itu, perlu adanya inovasi pembelajaran yang harus di laksanakan oleh peserta didik untuk dapat memperoleh nilai pengetahuan yang selaras dengan pembelajaran bahasa Inggris. Konsep multiliterasi perlu di aktualisasikan dalam pembelajaran bahasa Inggris yang menitikberatkan pada beberapa unsur yaitu kebahasaan, audio visual, spasial, dan gesture. Unsur-unsur tersebut merupakan bagian dari konsep multiliterasi yang seyogyanya harus di sampaikan ke peserta didik dalam sebuah pembelajaran akhir-akhir ini. Melihat permasalahan yang dihadapi oleh para santri yang belum sepenuhnya paham dengan esesi pembelajaran bahasa Inggris berbasis multiliteracies karena sebagian besar santri tidak mendapatkan akses penggunaan teknologi pembelajaran yang dapat dipergunakan setiap hari dalam rangka menunjang kegiatan pembelajaran di lingkungan pondok pesantren khususnya dalam pembelajaran bahasa Inggris. Namun, budaya literasi di lingkungan Pondok Pesantren saat ini tampaknya masih kurang dioptimalkan, hal ini dikarenakan pendekatan dalam pembelajaran yang masih berorientasi kepada hasil akhir bukan pada saat proses pembelajaran itu berlangsung (Anggraini, 2016). Berdasarkan permasalahan tersebut, konsep multiliteracies perlu di aktualisasikan dalam pembelajaran bahasa Ingggris yang melibatkan unsur kebahasaan, audio visual, spasial, dan gesture yang dapat dicontohkan dalam bentuk media dan platform pembelajaran yang merepresentasikan wujud penggunaan digital teknologi dalam pembelajaran bahasa Inggris yang mencerminkan konsep multiliteracies. Jadi, pengintegrasian pembelajaran bahasa Inggris dengan penggunaan digital teknologi dapat dijadikan solusi dalam mengatasi kebingunan belajar yang dialami oleh para santri atau keengganan belajar pada pembelajaran bahasa Inggris. Ini juga dapat memberikan wawasan baru bagi para santri agar dapat mengikuti trend dalam pembelajaran dalam jaringan atau virtual. Pembelajaran bahasa Inggris berbasis multiliteracies dapat berupa jenis pembelajaran virtual yang memanfaatkan media dan platform pembelajaran dalam jaringan atau virtual seperti Quizziz, Kahoot, Duolingo, You Tube, Zoom, dan Google Meeting yang dapat dipergunakan secara dalam jaringan atau luar jaringan. Pembelajaran multiliterasi diperlukan dalam upaya memahami dan menginterpretasi sesuatu sebagai sebuah kerangka atau suatu bentuk transformasi yang aktif dan dinamis dari dunia sosial yang kontemporer dan semakin beragam, dalam bahasa, visual, audio, gesture, dan ruang representasi yang semakin terintegrasi dalam media sehari-hari (Cope \& Kalantzis, 2009). Implikasi dari pedagogi multiliterasi ini berupaya untuk mendasari pergeseran makna dari konsep literasi. Di dalam konsep literasi yang lama, peserta didik menjadi penerima pasif atau hanya mengikuti apa yang diterima sebagai bentuk representasi yang otoriter dan kaku (Kalantzis \& Cope, 2008) (Cope \& Kalantzis, 2009) (Cope \& Kalantzis, 2016). Prinsip pedagogi literasi yang seperti itu hanya menciptakan suatu sistem sosial yang menyamaratakan semua peserta didik sebagai penopang suatu kediktatoran. Pembelajaran multiliterasi dapat diartikan sebagai proses representasi secara mandiri yang mengedukasi para peserta didik supaya ebih produktif, inovatif, dan kreatif dan diistilahkan sebagai sebuah pedagogi yang merdeka (Cope \& Kalantzis, 2009). Selanjutnya, pembelajaran multiliterasi merupakan suatu konsep yang fokus pada proses interpretasi makna yang bersikap aktif, transformatif, dan suatu pembelajaran yang menitikbertakan pada pemahaman untuk mengkaji pelajaran hidup yang terus berlangsung untuk menghadapi kehidupannya yang berubah dan beragam (Cope \& Kalantzis, 2009). Oleh sebab itu, model atau konsep pembelajaran literasi harus disosialisasikan kepada para santri agar memberikan pengaruh positif dalam pengembangan atau peningkatan kemampuan bahasa Inggris. 
BERNAS:

Jurnal Pengabdian Kepada Masyarakat

\section{Metode}

Metode yang digunakan dalam kegiatan pengabdian kepada masyarakat terkait dengan pelatihan atau sosialisasi yang fokus pada pemaparan pembelajaran bahasa Inggris berbasis Multiliteracies seperti penggunaan platform pembelajaran dalam jaringan (daring) 'Quizziz' dan pemanfaatan sosial media dalam pembelajaran bahasa Inggris. Subjek dari kegiatan ini merupakan para santri Pondok Pesantren Raudlatul Mubtadi'in yang berasal dari jenjang pendidikan sekolah dasar, menengah, dan perguruan tinggi. Pelaksanaan kegiatan ini berlangsung selama tiga hari yang mana hari pertama merupakan sesi pemaparan materi tentang pemanfaatan platform pembejaran dalam jaringan (daring) yang disampaikan oleh mahasiswa semester III Prodi Pendidikan Bahasa Inggris dan juga dosen pengampu mata kuliah 'Multiliteracies in Language Education'. Hari kedua fokus pada pemaparan materi tentang pemamfaatn sosial media dalam pembejaran bahasa inggris secara mandiri atau kelompok. Sedangkan, hari ketiga merupakan sesi yang bersifat evaluative dimana mahasiswa dan dosen mengukur tingkat pemahaman para santri dalam mengakses unsur multiliteracies dalam pembelajaran bahasa Inggris.

\section{Hasil dan Pembahasan}

Pada hari pertama kegiatan sosialisasi tersebut, mahasisw dan dosen sebagai pemateri menjelaskan langkah-langkah nyata dalam penggunaan platform pembelajaran bahasa inggris 'Quizziz' yang dapat dipahami oleh para santri seperti tata cara login ke system 'Quizziz', memasukan pin angka dalam system tersebut, dan juga tata cara pengerjaan soal yang dikemas seperti arena kompetisi. Platform dalam jaringan dapat digunakan dalam proses pembelajaran dalam jaringan secara regular dan dapat memberikan perubahan situasi pembelajaran yang menarik. Selain itu, pembelajaran daring, perlu memanfaatkan sebuah perangkat lunak maupun perangkat keras yang digunakan untuk mendukung kegiata pembelajaran online atau daring Ansori (dalam Herdiawan, R.D, 2021). Dalam hal ini, para santri dapat mengikuti dan memahami setiap arahan dan penjelasan dari Mahasiswa dan Dosen. Selama kegiatan berlangsung, para santri sangat antusias dalam berpartisipasi secara langsung dan juga banyak para santri yang aktif dalam bertanya dan menjawab setiap pertanyaan dari pemateri. Kegiatan inti dari sosialisasi pada hari pertama adalah melaksanakan pengerjaan soal materi bahasa Inggris melalui platform pembelajaran 'Quizzin' yang melibatkan seluruh santri di Ponpes Raudlatul Mubtadi'in. soal bahasa Inggris dikelompokan sesuai jenjang pendidikan dari para santri. Dalam pelaksanaannya, para santri nampak sangat bersemangat dalam mengikuti pengerjaan soal-soal bahasa Inggris secara dalam jaringan dengan menggunakan laptop atau ponsel-ponsel yang dimiliki oleh santri.

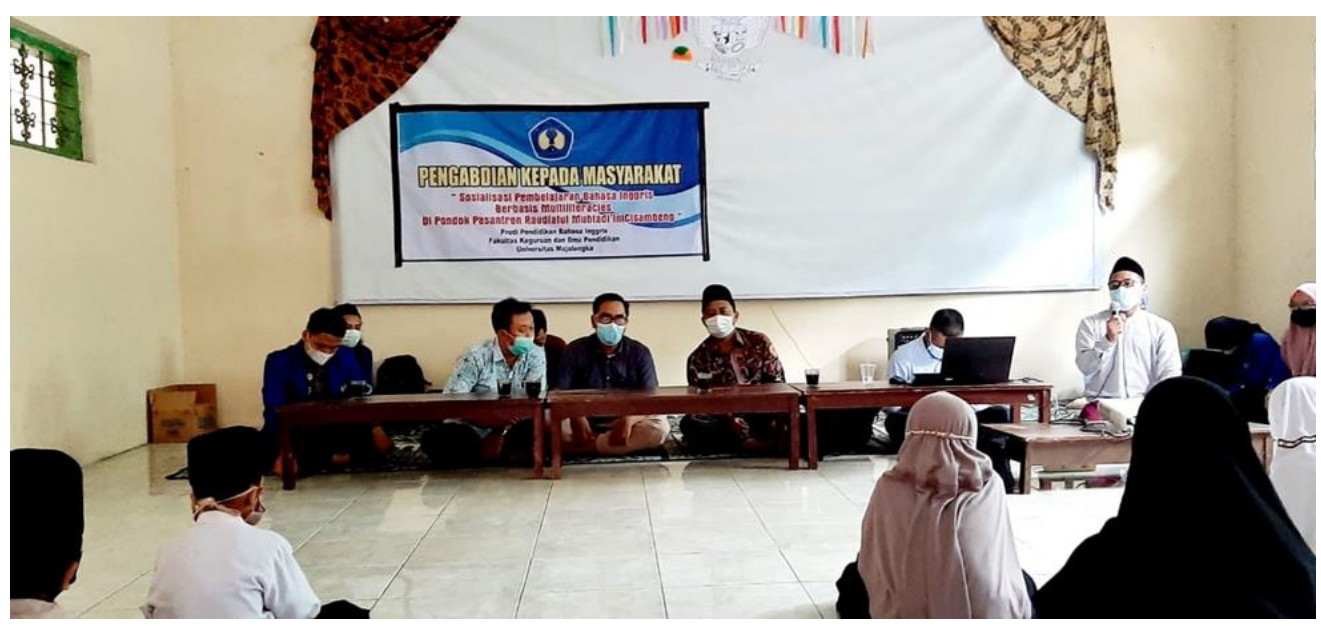

Gambar 1. Pemaparan materi tentang penggunaan platform dalam jaringan 
Sebelum tahap pengerjaan soal, santri dengan sendirinya dapat megikuti proses memasukan pin angka sebagai syarat daftar melalui system tersebut. Pemberian pengerjaan soal melalui Quizziz dapat meningkatkan minat belajar santri terhadap materi bahasa Inggris yang dapat dinamakan sebagai pembelajaran multiliteracies yang mengintegrasikan unsur teknologi didalamnya. Hal tersebut selaras dengan Morocco, et al (dalam Abidin, 2016: 33) yang menyampaikan bahwa dalam abad ke-21 ada empat kompetensi mempengaruhi manusia dalam menggali potensi dirinya yaitu kompetensi pemahaman yang tinggi, kompetensi berpikir kritis, kompetensi kolaborasi dan kompetensi berkomunikasi“". Selanjutnya kompetensi tersebut harus di dukung oleh keterampilan multiliterasi. Data tersebut merupakan pengembangan konsep dasar multiliteracies dari para santri yang didasari oleh konsep pedagogic bersifat unsur seni, cara pandang yang luas, dan kepandaian yang multiple. Menurut Abidin (2015) menegaskan bahwa pengembangan konsep multiliterasi dalam dunia pendidikan memiliki korelasi dengan konsep pedagogik berbasis seni, multiple ways of knowing, dan multipelintelegensi bagi siswa.

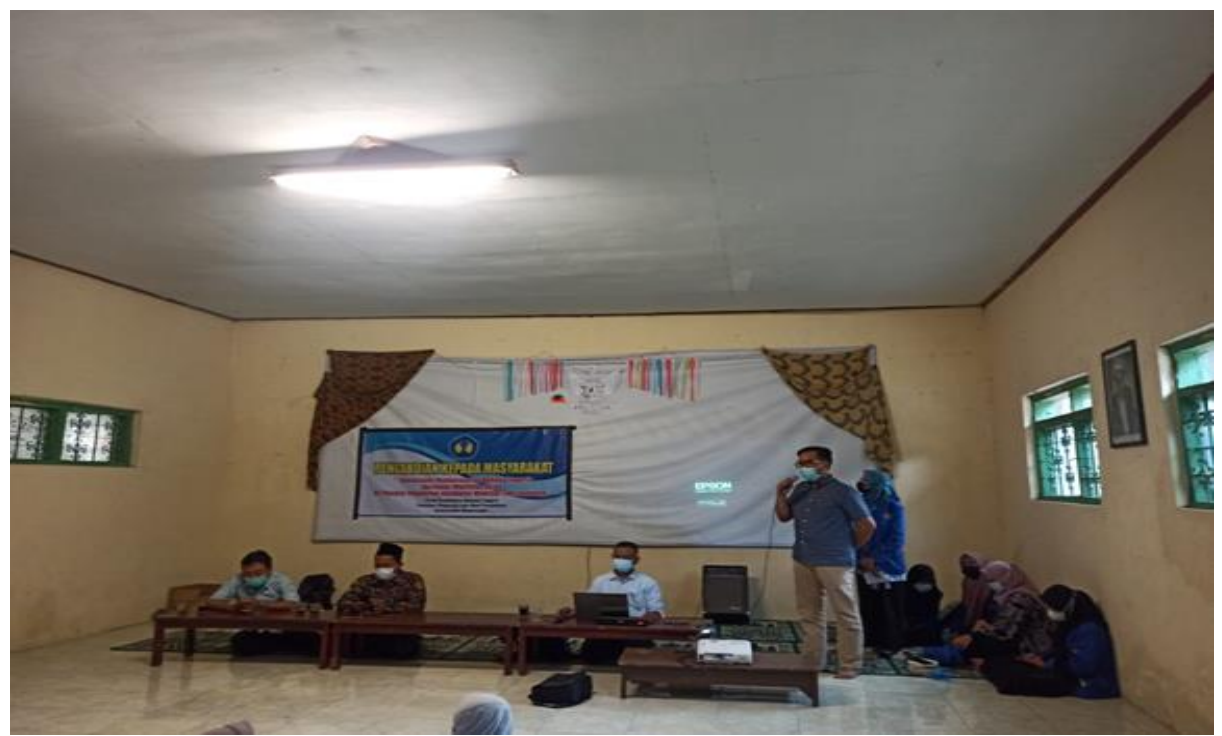

Gambar 2. Pemaparan materi tentang pemanfaatan sosial media

Pada hari kedua, kegiatan diisi oleh pemaparan yang berkaitan dengan penggunaan sosial media dalam pembelajaran bahasa Inggris. Dalam pelaksanaannya, para santri dibekali tata cara bersosial media yang bijak dengan memanfaatkan sosial media sebagai wahana belajar dalam peningkatan kemampuan berbahasa Inggris seperti pembuatan caption status yang bernuansa bahasa Inggris, dan juga pembuatan Reels atau Story dalam Instagram yang memiliki konten persuasive yang menggunakan bahasa Inggris. Serta penggunaan Whatsapp dalam pembelajaran bahasa Inggris contohnya belajar menulis paragraph sederhana dalam bahasa Inggris yang kemudian dibagikan di Whatsapp Group sehingga pemateri dan para santri dapat berinteraksi secara virtual melalui media tersebut. Sebagai pelopor konsep multiliterasi, New London Group 1996 dalam Pedagogy of Multiliteracies menyatakan bahwa "selain adanya konsep conventional reading and writing, digital literacy, visual literacy dan critical literacy menjadi aspek penting dalam praktik multiliterasi di kelas" (Abidin: 2015). Kemudian, hari ketiga fokus pada proses evaluasi yang mengukur pemahaman para santri dalam memanfaatkan atau menggunakan media dan platform pembelajaran yang merupakan wujud dari konsep multiliteracies. Dari kegiatan evaluasi tersebut, menyebutkan bahwa para santri mampu mengoperasikan atau menggunakan media ataupun platform pembejaran dalam jarring secara baik dan komprehensif. Sebagai contoh santri dapat membedakan berita factual dan berita Hoax yang mana itu mengindikasikan bahwa santri dapat memahami informasi dengan bijak dan sesuai fakta yang ada. Baker dalam (Jacobs, 2010) 
menjelaskan bahwa untuk menyiapkan diri dalam menangulangi penyebaran informasi yang sangat massif khusunya di dunia maya, para pendidik perlu mengedukasi peserta didiknya supaya mempunyai kemampuan dalam menyaring atau memahami informasi daring untuk menghindarkan peserta didik dari informasiinformasi yang tidak benar dan berisi propaganda yang dapat menjerumuskan terhadap sesuatu yang tidak baik, dan melatih nilai-nilai atau etika yang dapat menjadi dasar untuk pembelajaran membaca dan menulis.

\section{Kesimpulan}

Berdasarkan hasil kegiatan sosialisasi tersebut, para santri dapat mengembangkan potensi diri dalam pemanfaatan teknologi pembelajaran yang dapat diakses secara dalam jaringan. Santri juga dapat menggunkan kemampuan berpikir kritis dalam upaya pemanfaatan sosial media dalam pembelajaran bahasa Inggris. Konsep multiliterasi dapat diimplementasikan dalam bentuk pengintegrasian peran digital teknologi dengan materi yang terkait dan berkontribusi pada peningkatan wawasan baru dalam pemanafaatan sosial media dalam melaksanakan pembelajaran bahasa Inggris atau bias dikatakan mahasiswa diarahkan menjadi pribadi yang multiliterate yang mana mahasiswa mampu menciptakan lingkungan belajar yang bernuansa multiliterasi pada abad ke 21 ini.

\section{Daftar Pustaka}

Anggraini, S. (2016). Budaya literasi dalam komunikasi. Wacana.

Abidin, Y. (2015) Pembelajaran Multiliterasi: Sebuah Jawaban Atas Tantangan Pendidikan Abad Ke21. Bandung: Rafika Aditama.

Abidin, Y. (2016) Revitalisasi Penilaian Pembelajaran Dalam Konteks Pendidikan Multiliterasi Abad ke21. Bandung: Rafika Aditama.

Cope, B., \& Kalantzis, M. (2005). Multiliteracies: Literacy Learning and the Design of Social Futures. In Multiliteracies: Literacy Learning and the Design of Social Futures. https://doi.org/10.4324/9780203979402

Cope, B., \& Kalantzis, M. (2009). "Multiliteracies": New Literacies, New Learning. Pedagogies: An International Journal. https://doi.org/10.1080/15544800903076044

Cope, B., \& Kalantzis, M. (2016). A pedagogy of multiliteracies: Learning by design. In A Pedagogy of Multiliteracies: Learning by Design. https://doi.org/10.1057/9781137539724

Jacobs, H. H. (n.d.). Media Literacy: 21st Century Literacy Skills, Curriculum 21 st Essential Education For A Changing World (hlm. 133-152). Virginia: ASCD

Kalantzis, M., \& Cope, B. (2008). Language Education and Multiliteracies. In Encyclopedia of Language and Education. https://doi.org/10.1007/978-0-387-30424-3 15

Herdiawan, R. D. (2021, September). Platform Pembelajaran Daring Dalam Masa Pendemi Covid 19 Pada Perkuliahan Teaching Internship. In Prosiding Seminar Nasional Pendidikan (Vol. 3, pp. 29-32). 